\title{
Wanted: A Standard for Virtual Patent Marking
}

Gaétan de Rassenfosse

Kyle Higham

March 2020

Innovation and Intellectual Property Policy Working Paper series no. 7

Available at: https://ideas.repec.org/p/iip/wpaper/7.html 


\title{
Wanted: A Standard for Virtual Patent Marking
}

Gaétan de Rassenfosse and Kyle Higham*

\begin{abstract}
Patent marking is used by patentees to provide a form of notice to the public about the existence of a patent and can increase damages awarded in cases of infringement. Historically, marking is done by listing the associated patents on the product they cover. Virtual patent marking (VPM), or web marking, offers patentees a convenient alternative to this practice by allowing patentees to place a web address, linking to a list of the associated patents, on the product instead of the static patent list. However, due to uncertainty in the legal community about proper implementation, adoption has been slow, despite broad agreement on their many advantages over traditional marking. In this article, we lay out guidelines for the proper implementation of VPMs and call for a formal standard to encourage their adoption.
\end{abstract}

Keywords: patent notice, product, standard, virtual patent marking, webmarking

\footnotetext{
${ }^{*}$ Ecole polytechnique fédérale de Lausanne, Switzerland. Emails: gaetan.derassenfosse@epfl.ch; and kyle.higham@epfl.ch. The authors are grateful to Emma Francis, John Liddicoat, and Ling Zhao for their very helpful comments. This paper has been writing as part of a project funded by the Swiss National Science Foundation (grant number 10DL12_183088). The paper exploits data from the IPRoduct project, which has received funding from the U.S. National Science Foundation (award number 1645264), the Swiss Federal Institute of Intellectual Property, the European Patent Office Academic Research Programme, and the Sloan Foundation under the $\mathrm{I}^{3}$ initiative.
} 


\section{Introduction}

Patent marking has a long history in the intellectual property (IP) laws of many jurisdictions. In the United States, for example, the marking statute has remained in roughly its current form for almost 100 years. ${ }^{1}$ A patent mark is a form of 'constructive notice,' in short, a way to make information regarding the existence of a patent readily available such that a reasonable person will easily find this information through ordinary care and diligence. ${ }^{2}$

Patent marks, therefore, prevent potential infringers from claiming they were unaware that they were trespassing on someone else's intellectual property. This unintentional infringement defence could otherwise limit the recovery of damages. ${ }^{3}$ Marking a product allows firms to claim damages back to the time when either the infringement or the marking began (whichever is later), ${ }^{4}$ rather than from the time the infringer received formal notice.

Historically, marking a product required the manufacturer to write the relevant patent numbers on the product or packaging, but the past decade has seen a fundamentally new kind of marking gain popularity. First introduced in the United States via the America Invents Act (AIA) of 2011, and implemented the following year, virtual patent marks (VPMs) offer patent owners a more convenient way to mark their products. However, this legislative change comes with a significant amount of confusion as to how to use VPMs and ensure their functionality, and those wanting to do so must grapple with many new questions that simply are not of concern when using traditional marking. Further, answers to these questions, when answers exist, are often not straightforward, and the legal community has promoted caution and forethought before deciding to make use of VPMs. ${ }^{5} \mathrm{We}$ argue that the adoption of VPMs has been slow as a result.

A standard would provide clear guidance on the way VPMs should be formatted in order to avoid both known pitfalls and those likely to arise in the future. Standardised formatting would make the implementation of VPMs more straightforward, particularly for small businesses who might be reluctant to pay for legal advice on the matter. More broadly, if a global standard was established, then patent marking could eventually be consistently digitised in all jurisdictions, removing some frictions associated with ensuring the relevant constructive notice is in place across multiple jurisdictions. Lastly, a standard would lower the barriers to the adoption of VPMs by policymakers in VPM-absent jurisdictions. If realised, these factors would result in an increased rate of VPM adoption. A standard would bring greater transparency of IP ownership, lower costs of constructive notice for

\footnotetext{
${ }^{1}$ MJ McKeon, 'Patent Marking and Notice Statute: A Question of Fact or Act' (1996) Harv. JL \& Tech. 9, 429.

${ }^{2}$ In the context of patent law, this can be contrasted with 'actual notice,' whereby an infringer receives notice directly and unambiguously. This can be achieved by, for example, serving a cease and desist notice to the infringer in person.

${ }^{3}$ Note that unintentional infringement is not a defence against infringement claims.

${ }^{4} \mathrm{Up}$ to a limit of six years before the formal filing of the infringement complaint.

${ }^{5}$ E.g., S Simmons, 'Real Problems with Virtual Patent Marking' < https://www.medtechintelligence.com/feature article/realproblems-with-virtual-patent-marketing/> accessed 3 March 2020
} 
patentees, higher penalties for infringing on commercialised IP, and more efficient trade between jurisdictions.

We aim this article at those patentees and attorneys who wish to ensure the proper implementation of VPMs, and also at governments or inter-governmental organisations who wish to construct a formal standard for VPMs or otherwise encourage their use. The United States has by far the most VPM users and VPM-related case law, and we therefore believe that this jurisdiction's experience can provide some important lessons for the global intellectual property community. Indeed, the content and wording of the U.S. and U.K. statutes that explicitly allow VPMs as a form of valid mark are largely the same.

The remainder of this article will concern itself with the purpose and format of these new types of marks, and details the need for a formal standard before suggesting some essential components of such a standard. We then examine the current state of VPMs by characterising a sample of active patent marking web pages and estimate the number that would not function as VPMs should they be relevant to an infringement case. Finally, we discuss the outlook for VPMs going forward and suggest some prudent policies that governments may implement to encourage their uptake.

\section{Virtual patent marking}

Virtual patent marks are straightforward in theory: instead of physically marking each product with the associated patent numbers, the marking statute now allows patentees to simply point to a webpage where the patents are listed. The wording of the relevant section of the marking statute, as modified by the AIA, is as follows:

"Patentees and persons making, offering for sale, or selling within the United States any patented article for or under them, or importing any patented article into the United States, may give notice to the public that the same is patented, either by fixing thereon the word 'patent' or the abbreviation 'pat,' together with the number of the patent, or by fixing thereon the word 'patent' or the abbreviation 'pat.' together with an address of a posting on the Internet, accessible to the public without charge for accessing the address."

(35 USC s 287(a))

Observers noted that the addition of virtual marking to the original 2009 bill in the U.S. Senate did not receive a single mention throughout the legislative process. ${ }^{6}$ This lack of attention now manifests itself through a lack of clarity on how to properly construct a virtual patent mark. Note that while we

\footnotetext{
${ }^{6}$ C McCaffrey, 'The Virtues of Virtual Marking in Patent Reform' (2011) Nw. UL Rev. 105, 367.
} 
often refer to VPM pages as webpages throughout this article, a URL that points to an equivalent PDF document will suffice under 35 USC s 287(a).

VPMs as a concept, however, have some clear advantages over traditional marking. Perhaps most obviously, they make the process of updating patent-product associations very simple and cheap. Before the AIA, manufacturers wishing to mark their products would need to retool their machines or develop new moulds to reflect these updates. These modifications can come at a high cost. In not doing so, however, patentees risk an accusation of false marking. In a prominent false marking case, for example, the Solo Cup company claimed that retooling the manufacturing process to reflect changes in patent status would cost the firm in excess of $\$ 500,000 .{ }^{7}$ VPMs remove the need for such retooling while enjoying the benefits associated with patent marking and reducing the risk of a false marking suit.

There are many cases where updates to existing patent marks may be necessary, from the obvious cases of patent expiry ${ }^{8}$ or invalidation to more subtle scenarios: a challenged patent that is not invalidated may instead be narrowed such that it no longer covers the marked products, ${ }^{9}$ or perhaps the manufacturer simply makes a mistake. Updates to patent marks are also pertinent in the case of newly granted patents, as the use of VPMs means that there is no delay in adding the granted patent number to associated products. This advantage is significant, as damages can only be recovered from the time the patent number is consistently marked on the product. ${ }^{10}$ Not only does it take time to retool or otherwise add the mark to the product/packaging, but in cases where the same products were previously unmarked, it also takes time for these newly marked products to displace the unmarked ones in the supply chain. ${ }^{11}$

VPMs, when they are valid in, and compatible between, multiple jurisdictions, also have a significant benefit to firms selling the same products in these jurisdictions. ${ }^{12}$ The United Kingdom, for example, has also integrated virtual patent marking into their Intellectual Property Act (2014):

"... a person shall not be taken to have been so aware or to have had reasonable grounds for so supposing by reason only of the application to a product of the word 'patent' or 'patented,' or any word or words expressing or implying that a patent has been obtained for the product, unless the number of the patent or a relevant internet link accompanied the word or words in

\footnotetext{
${ }^{7}$ Pequignot v. Solo Cup Co., 608 F.3d 1356 (Fed. Cir. 2010).

${ }^{8}$ While there is case law in the United States that indicates the marking of expired patents does not constitute false marking (35 USC 292(c)), this is not true in other jurisdictions such as the United Kingdom (United Kingdom Intellectual Property Office Manual of Patent Practice, Section 110.03). In the latter case, an appropriate grace period is given to patentees to allow for the removal of these marks - if the mark is a VPM, an appropriate grace period could be very short indeed. ${ }^{9}$ McCaffrey (n 6); AM Joshi and I Hemmatian, 'How do legal surprises drive organizational attention and case resolution? An analysis of false patent marking lawsuits' Research Policy 47(9), 1741-1761.

${ }^{10}$ American Medical Systems v Medical Engineering Corp., 6 F 3d 1523 (Fed. Cir. 1993).

11 ibid

12 J Liddicoat, 'Re-evaluating innocent infringement in Australia: Patent numbers and virtual marking' Australian Intellectual Property Journal 25, 18.
} 
question." This passage is followed by: "The reference ... to a relevant internet link is a reference to an address of a posting on the internet;

(a) which is accessible to the public free of charge, and

(b) which clearly associates the product with the number of the patent."

This Act appears to be compatible with the U.S. version. Without the VPM option, a patentee selling the same patented product in both the United States and the United Kingdom would have a choice: include different patent marks depending on where the product is being sold, or mark both patents on the product or packaging. The former option is logistically complex, whereas the latter option may not feasible for products covered by multiple patents in each of many jurisdictions. VPMs allow the mark to be a single internet link, leading to a webpage listing all patents associated with the product in all jurisdictions. From a practical standpoint, VPMs take up as much space on the product packaging as a single patent mark. For any product covered by multiple patents, therefore, virtual marking is much more space-efficient and may allow patent marking on products that previously did not have enough space to list all relevant patents clearly.

Lastly, contemporary jurisprudence concerning patent marking is often not concerned with how products are marked, but rather what needs to be marked. Both consensus and ongoing debate on this topic apply to VPMs as much as they do to traditional marking. For example, marking traditionally applies only to product patents; a process patent does not generally cover the product that results from the patented method. ${ }^{13}$ However, this area of U.S. patent law is not entirely settled, ${ }^{14}$ and some firms have used this ambiguity to their advantage in claiming damages on unmarked items. ${ }^{15}$ For our purposes, any precedent around these issues which does not directly relate specifically to the way products are marked cannot be addressed by a patent marking standard and is therefore not of concern here.

\section{The need for a virtual patent marking standard}

Virtual patent marking statutes are clear about how a VPM URL should appear on the products they mark. However, they provide very little instruction about how the website listing the patents should appear. As a result, patentees have taken various strategies in their attempts to satisfy the requirements of these statutes.

\footnotetext{
${ }^{13}$ The patentee needs to first provide evidence that (1) a substantial likelihood exists that the product was made by the patented process, and (2) the patentee has made a reasonable effort to determine the process actually used in the production of the product and was unable so to determine. In this case the burden shifts to the alleged infringer to show that the product was not the result of the patented process (35 USC 295).

${ }^{14}$ C Sharkey, 'Strategic Assertions: Evading the Patent Marking Requirement' (2014) Nw. J. Tech. \& Intell. Prop. 12(1), 103.

${ }^{15}$ Mformation Techs., Inc. v Research in Motion Ltd., 830 F. Supp. 2 d 815 (N.D. Cal. 2011).
} 
VPMs are still in their infancy and adoption has been slow. ${ }^{16}$ However, they have already been tied up in several legal cases, ${ }^{17}$ highlighting the need for explicit guidelines to ensure that VPMs function as intended. Presently, a patentee wanting to set up a VPM page has precious little information to guide their efforts. Many of the following concerns substantiating a need for a standard were brought to light by McCaffrey $(2011)^{18}$ before the AIA was even enacted. Another significant work that contributes to the current article is the 2014 United States Patent and Trademark Office (USPTO) report written to satisfy a follow-up requirement laid out in the AIA, which cites McCaffrey $(2011)^{19}$ extensively and makes it abundantly clear that the concerns in the latter article remain pertinent and should be addressed. As of writing this article in the year 2020, this gap has not been filled; as more firms adopt VPMs, the legal aspects of these problems are starting to crystallise in the form of lawsuits.

We must emphasise that the current article is not the first call for a VPM standard. In fact, while academic and grey literature on the topic of VPMs is still sparse, many of these documents either lament the obvious lack of standards or explicitly suggest that some standards need to be put in place. ${ }^{20}$ The 2014 report from the USPTO states that " $[\mathrm{t}]$ he use of a standard format for virtual marking Web pages may alleviate some of the difficulties in establishing the statutorily require association between the patented article and the number of the patent". ${ }^{21}$ However, association is just one potentially problematic aspect of VPMs that could be remedied with a standard.

The remainder of this section details current ambiguities, as illustrated in the extant academic literature and jurisprudence, in virtual patent marking as it is currently practised. These ambiguities are not only inconvenient to patentees and may prevent the uptake of VPMs generally, but in some cases have actively done financial damage to patentees who thought they were compliant. There is no good reason to let the following issues stand, and established guidelines will have obvious benefits for patentees, the public (including potential infringers), and the courts.

\section{Privacy Concerns}

Before VPMs, a potential infringer could simply read a patent number marked on a competitor's product, then go to a patent information database to find detailed information about the specific technical claims of the patent. However, VPM websites are generally hosted by the patent owner, and with this ownership comes the ability to see the approximate physical location of most visitors to the

\footnotetext{
${ }^{16} \mathrm{G}$ de Rassenfosse, 'Notice failure revisited: Evidence on the use of virtual patent marking' (2018) National Bureau of Economic Research Working Paper, w24288.

${ }^{17}$ For example, Manufacturing Resources International, Inc. v. Civiq Smartscapes, 397 F. Supp. 3d 560 (D. Del. 2019); Asia Vital Components Co. v. Asetek Danmark A/S, 377 F. Supp. 3d 990 (N.D. Cal. 2019); A to Z Machining Service, LLC v. National Storm Shelter, LLC, No. CIV-10-422-C (W.D. Okla. 2011).

${ }^{18}$ McCaffrey (n 6)

19 ibid

${ }^{20}$ See, e.g., McCaffrey (n 6); M K Lee, 'Report on virtual marking' (2014) Report to Congress prepared by the United States Patent and Trademark Office. $<$ https://www.uspto.gov/sites/default/files/aia implementation/VMreport.pdf $>$ accessed 3 March 2020.

${ }^{21}$ Lee, ibid
} 
VPM page. Many VPM pages also conveniently contain links to the full patent information hosted by the patent office. In this scenario, a patentee could not only note that an employee at a competing firm is interested in the patents associated with a particular product, but could identify the specific patents and products in which they were interested. More perniciously, McCaffrey $(2011)^{22}$ has noted that tracking in this manner could be brought up in court as evidence of notice.

In fact, the only legal restriction regarding privacy or accessibility of a VPM page is that it must be "accessible to the public without charge." As noted by both McCaffrey (2011) $)^{23}$ and USPTO (2014), ${ }^{24}$ there is nothing stopping firms hosting VPM pages from requiring a kind of free registration in order to access the page.

Yet, these issues undermine the whole concept of constructive notice by making it more challenging to conduct due diligence with regard to knowledge of existing patents. As such, a standard must address how VPM website visitor information is managed.

\section{Technical Concerns}

A website, unlike a physical mark, is vulnerable to both attacks and technical failures. For example, U.S. precedent prescribes that patent marks, including virtual marks, must be "substantially consistent and continuous" once marking on a particular product begins. ${ }^{25}$ In the context of VPM websites, this requirement elicits several questions. First, if the VPM website is not accessible, whether due to maintenance or unanticipated technical problems, can we consider this marking to be 'continuous'? Second, how does a patentee, or indeed an infringer, prove the state of the website at any given point in time? Lastly, if the information on the website is changed, or otherwise made unavailable or inaccurate, how is this situation remedied in light of the continuity requirement?

In the United States, the law only specifies that the link marked on the product be "an address of a posting on the Internet," which does not imply that the patentee is required to host the website themselves. A third party that specialises in the hosting of VPM pages could assume responsibility for the security and stability of the website, technically and legally. If the patentee wishes to host the VPM site, however, they will need to take responsibility for the stability and security of their webpages to ensure that the VPMs satisfy the continuity and consistency requirements of patent marks - marking is only useful if the information is always accessible, and accurate. ${ }^{26}$

In any case, a VPM standard should give some guidance to patentees as to the technical issues that could arise when hosting a VPM page and their potential legal ramifications.

\footnotetext{
${ }^{22}$ McCaffrey (n 6)

23 ibid

${ }^{24}$ Lee (n 20)

${ }^{25}$ American Medical Systems (n 10)

${ }^{26}$ If the website is subtly changed by a bad actor without being noticed, the affected information may no longer constitute constructive notice. Of course, conventional security measures to prevent unauthorised modifications to websites apply to VPM pages.
} 


\section{Legal Concerns}

The wording of patent marking laws being vague as to the format of the VPM webpage, we must interpret (or reinterpret) the legal meaning of particular words within these laws for the VPM context. In one recent case, for example, the court determined that even with qualifying text (e.g., "Our products are covered by one or more of the following patents"), a list of all patents that the firm owns does not sufficiently "associate the patented article with the number of the patent." ${ }^{27}$ While one might have assumed this kind of association to be necessary, it is not immediately apparent that it should be, based on the language of the law. After all, the link listed on the product did, if indirectly, associate the article with the number of the patent — the relevant patent number was just hidden among others.

In the context of patent marking, case law, by its nature, while highlighting marking practices that do not meet the requirements, say little about what would do so. In the case described above, it is now clear that a website that simply lists a firm's patents without mention of the products each one covers does not constitute 'association' between product and patent. We may also assume that this 'association' requirement is unidirectional - a patentee does not appear to be obligated to ensure patents can be linked to all the products they cover, even though this may be useful for constructive notice. In fact, the primary outcome of this case, for the purposes of a standard, is the clarification of the formatting and informational requirements of a VPM webpage. These requirements were not made explicit prior to this case being decided. In order to correctly associate patents with products, a firm must include on the VPM webpage both the product name and the associated patent numbers in a format that makes clear the connection between these two sets of identifiers.

The 'continuity' of marking also elicits an interesting legal question in the context of VPMs. Specifically, concerns regarding the accessibility of VPM URLs over time may be the subject of scrutiny in future infringement cases. As of the beginning of 2020, however, this has not occurred. In fact, in one case, evidence regarding the date of the initial set-up of the VPM page was presented, and as there was no evidence of downtime, this was determined to be sufficient to fulfil the continuity requirement from that point in time ${ }^{28}$. There was also no evidence concerning what was actually listed on the website, nor any details about changes that may have been made since the site was set up. If the norms related to these aspects of VPM pages change, perhaps in response to a formal standard, then this precedent may not be adhered to in the future. For example, a patentee pursuing infringement damages, and claiming their VPM constitutes constructive notice, may soon have to provide evidence concerning the time at which a particular patent is added to the VPM page.

Technology licensing also introduces some interesting legal questions in the context of patent marking. Marking licensed patents on a product can easily be built into the licensing contract; however, if a licensee wishes to use a VPM then this arrangement is more complex. For example,

\footnotetext{
${ }^{27}$ Manufacturing Resources International, Inc. (n 17)

${ }_{28}$ Asia Vital Components Co. (n 17)
} 
there may have to be negotiation around the VPM URL: should it point to the website of the patent owner, or that of the licensee? In any case, if a licensed patent is listed on a licensee's VPM page alongside non-licensed patents, the ownership status of this patent should be made clear.

This is all to say that it is entirely possible that many VPMs as currently implemented will not satisfy future jurisprudence. To avoid these potential pitfalls, a standard should provide guidelines that anticipate such potential clarifications of the law as written. To this end, both the informational content and the formats of all components of a VPM webpage should be standardised.

\section{Current state of virtual marking pages}

Before laying out the essential components of a virtual patent marking standard we will first evaluate the current state of patent marking pages. Here, we obtain a random sample of virtual patent marking pages, taken from the IPRoduct database, ${ }^{29}$ to examine the main issues that currently affect the functionality of VPM pages. All VPM pages considered here have been manually identified as such; that is, the page owners have specified that the list of patents existed for the purposes of notice under the relevant statute. ${ }^{30}$

In light of the concerns discussed above, we are able to directly observe two crucial aspects of a functional VPM page: URL accessibility and association between products and patents. The first is vital - if a VPM URL written on a product does not lead to a page with a list of patents, then the product may not be considered marked at all. The second is based on recent U.S. case law. ${ }^{31,32}$

Accessibility can be difficult to measure. Fortunately, as IPRoduct has been indexing VPM pages for about three years, we can start to quantify the size of this problem. We first check the state of all VPM pages in the IPRoduct database to see how many are currently accessible. We find that only about four per cent of pages are now completely inaccessible. However, a more pernicious problem arises when we consider VPM pages that are redirected to a non-VPM page. To estimate the prevalence of this problem, we randomly select $50 \mathrm{VPM}$ pages that redirect to a new page than the one that was originally indexed by IPRoduct, each manually verified to be intended for patent marking at the time that they were first indexed. All of these pages redirect to either a different page in the same domain, a "page not found" notice within the same domain, or a new domain entirely (e.g., in the case of mergers, acquisitions, or rebranding). We find that only 58 per cent of redirects in this sample lead to another VPM page. Scaling this to the whole IPRoduct database (of which 23 per cent of URLs redirect), this implies that about 13 per cent of VPM pages that were available at some

\footnotetext{
${ }^{29}$ IPRoduct $<$ http://www.iproduct.io $>$ accessed 3 March 2020

${ }^{30}$ There exist lists of product-patent associations online, however, as their purpose is not explicitly identified as patent marking, we exclude these from our random samples.

${ }^{31}$ Manufacturing Resources International, Inc. (n 17)

${ }^{32}$ Note that the association requirement is even more explicit in the United Kingdom's VPM legislation, so the following analysis is generalisable to this jurisdiction as well.
} 
point in the past three years now cannot function as patent marks, as the products marked with these URL will not lead to a list of patents.

Of those pages that are accessible, we can estimate the number that meet the association requirement. After checking that the patent list is meant to function as a VPM page, we check whether it meets the two following criteria:

- The marked products are listed by name or code;

- The correspondence between the product(s) and the associated patent(s) is clear (in either direction). ${ }^{33}$

We find that about 24 per cent of self-declared virtual patent marking pages do not meet these basic requirements. These pages are at high risk of not being able to function as notice should an infringement case arise that concerned a listed patent.

Thanks to these data, it is possible to calculate an approximate probability that a given VPM page will function as intended. On top of the baseline non-functionality of pages that don't meet the associate requirement as defined above, the likelihood that the URL is either dead or has been redirected to a non-VPM page increases with time. Splitting the VPMs in the IPRoduct database by years since index, we estimate that the probability of any given VPM page being inaccessible increases by 7-10 per cent every year. ${ }^{34}$ For example, if we add this rate to the underlying baseline of non-functional (but accessible) VPM pages, the chance that a VPM page that was accessible three years ago is currently accessible and functional as a VPM is 55-60 per cent.

In summary, there is a high probability that a given URL on a product that the manufacturer intended to function as a VPM is, for legal purposes, unmarked; due either to instability of the listed URL or to such poor implementation that a court may find (and has found in the past) such a mark to be invalid. ${ }^{35}$ This probability increases with time, from about 27 per cent for VPMs that are less than one year old to over 40 per cent for those that are three years old.

\section{Proposed guidelines for a standard}

This section outlines what we consider to be essential components of any future standard for virtual patent marking. The primary reason for a standard is to give patentees confidence that their VPM webpages fulfil the requirements of the relevant laws. We are also hopeful that such a standard would

\footnotetext{
${ }^{33}$ Note that this is a relaxed definition of association; to emulate a traditional patent mark, each product should have associated with it a list of patents, and not vice-versa.

${ }^{34}$ This rate is far higher than the exit rate for even new patenting firms (C Helmers and M Rogers, 'Innovation and the Survival of New Firms in the UK' (2010) Rev. Ind. Organ. 36(3), 227-248), and most of the firms in the IPRoduct database are well-established. However, this rate is slightly lower than the hazard rates found for the death of URLs in legal or technical documents (S Rhodes, 'Breaking down link rot: the Chesapeake project legal information archive's examination of URL stability' (2010) Law Libr. J. 102, 581; J Zittrain, K Albert, and L Lessig, 'Perma: scoping and addressing the problem of link and reference rot in legal citations' (2013) Harv. L. Rev. F. 127, 176). This difference is perhaps to be expected when the same entity controls the listed URL and the website it links to and there is a strong financial incentive for the entity to ensure the link survives.

35 e.g., Manufacturing Resources International, Inc. (n 17)
} 
assist in broader adoption of VPMs, both by patentees in jurisdictions where they are an option and by governments that are currently considering similar legislation. After all, despite the many problems and ambiguities of virtual marking as currently practised, it is difficult to argue against the concept itself.

These guidelines may be adopted by firms, third-party VPM service providers, or even centralised government-provided services that may exist in the future. Therefore, the standard must be simple to adhere to, such that the benefits of VPMs over traditional marking are not outweighed by the costs of setting up and maintaining a VPM website. An example of a good VPM page is shown in Figure 1.

Figure 1. An example of a VPM webpage satisfying the directly the observable characteristics prescribed in Section 5

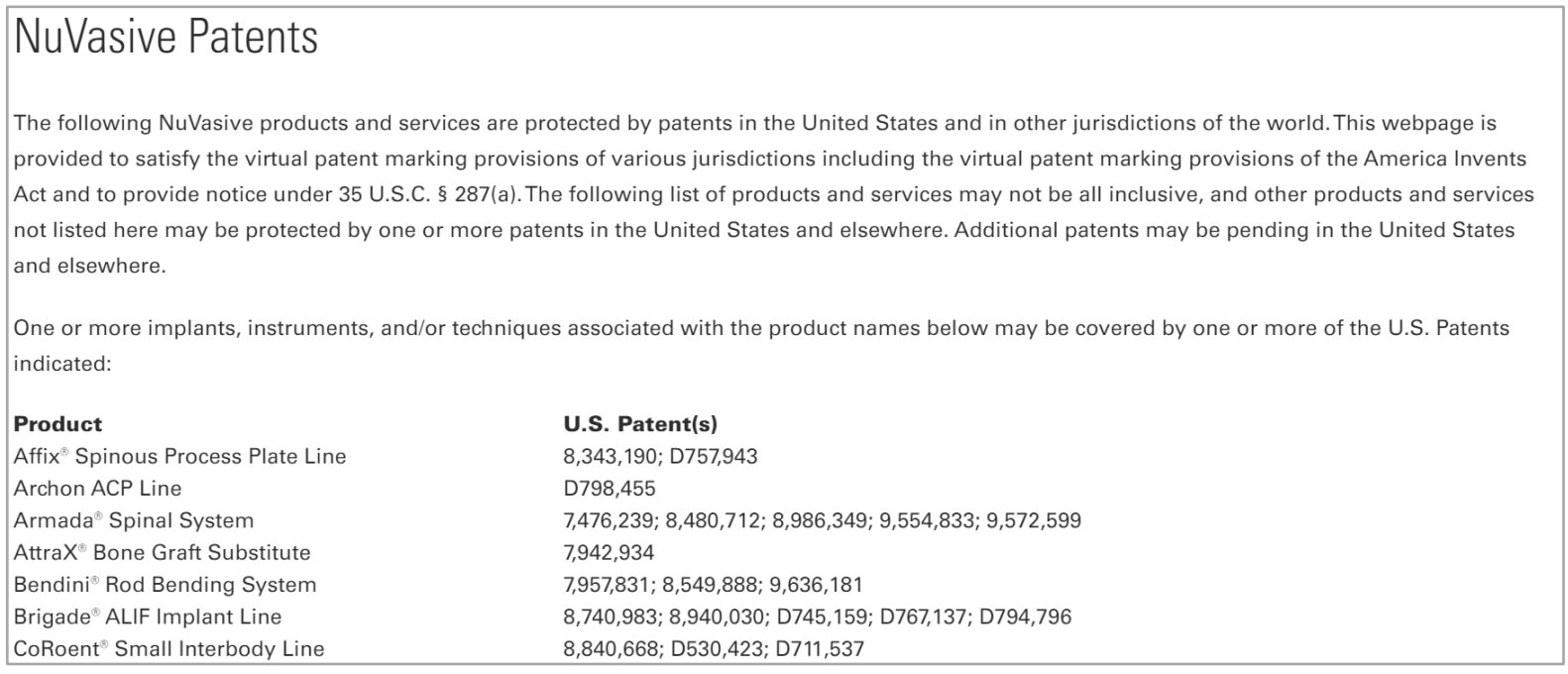

Source: Print screen from NuVasive website, <https://www.nuvasive.com/resources/virtual-patent-marking/>, March 2020.

\section{Essential Components of a Standard}

1. Identification of virtual patent marking pages. A patent marking page should first be identifiable as such, so that there is no ambiguity about its purpose. When the purpose of the page is made clear, an infringer will find it difficult to argue that they were not aware that the URL on the product, and the associated online patent list, constituted constructive notice. Towards this end, a standard introduction and disclaimer as to the purpose and content of the webpage should be overtly displayed somewhere on the page (ideally the top). This introduction should mention 'Virtual Patent Marking,' 'Webmarking,' or other regional variants, and, for additional clarity, should also mention the specific laws, statutes, or acts to which the page aims to adhere. An example is as follows: "This page is intended to provide virtual patent marking and to serve as notice under 35 USC s 287(a)." This sentence ensures 
that a patentee's intent to mark the product is apparent, and makes visitors aware of the relevant law.

2. Standard format of patent numbers. Patent numbers should be displayed in a standard format, such as that prescribed by the World Intellectual Property Organisation (WIPO). ${ }^{36,37} \mathrm{~A}$ standard format will make it easy for anyone viewing the VPM page to identify the jurisdiction that has granted the patent and the kind of document listed (e.g., utility patent, design patent or a reissue). This measure will facilitate an online search for further information about the technical content covered by any listed document. In line with the WIPO standards directed at patent issuing offices, each document should be identified with the two-letter code of the issuing office or organization, the full document number, and the document kind code (e.g., US7071258B1). If all documents listed have been granted by the same jurisdiction and are of the same kind (e.g., if all patents are U.S. utility patents), then a note preceding the list stating this fact is sufficient.

3. Standard format of product identification. The product or product range with which each patent is associated should be easily identified. This identification can be a unique name used for each product or product range; however, this should be paired with a unique product number such as a Universal Product Code or an internal catalogue number that is easily associated with the relevant product (e.g., through its barcode) to minimise ambiguity. This measure is to ensure the VPM page meets the association requirement.

4. Product-patent correspondence. The association between product and patent should be clear in order to satisfy current VPM laws and function as constructive notice. At present, many VPM pages state, "Our products are covered by one or more of the following patents or pending patents," followed by a list of patents. This practice is known to be insufficient for constructive notice due to a lack of clear association between product and patent. ${ }^{38}$ Instead, VPM pages should take the form of a table whereby products are listed in the first column and associated patents in the second. This correspondence is advised because the VPM URL is marked on a particular product, and the visitor would like to see which patents are associated with that particular product - a patent-product association may not serve as a clear association. In the case of product ranges where every product in the range is covered by the same set of patents (and not a subset), one row may be used to describe this relationship. In all other cases, each product should be listed in its own row. Where possible, an additional column containing the unique identifiers associated with each product or range will provide additional clarity to ensure adherence to the association requirement.

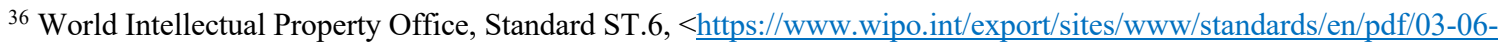
01.pdf $>$ accessed 3 March 2020

37 World Intellectual Property Office, Standard ST.16, <https://www.wipo.int/export/sites/www/standards/en/pdf/03-1601.pdf $>$ accessed 3 March 2020

${ }^{38}$ Manufacturing Resources International, Inc. (n 17)
} 
Further, all patents on the VPM page should be active; that is, not invalidated, lapsed or expired. This will minimise the risk of false marking accusations, particularly in jurisdictions such as the United Kingdom which have strict laws regarding false marking that don't require any intent to deceive the public.

5. Ensuring anonymity. Patentees should not use their VPM website to collect and store information about its visitors, including but not limited to a registration requirement or cookies. In the United States, for example, it is not clear that a VPM website that collects visitor information is "accessible to the public without charge." If this information is something of value to both the patent owner and the visitor (such as a competitor), then it may be argued that an exchange has taken place, which could be construed as a 'charge' in future legal cases. An exception may be made for age-checks that are required by law in many jurisdictions, such as those that apply to alcohol or cigarette vendors.

6. Ensuring and documenting continuity. To satisfy the continuity requirement as prescribed by precedent in the United States, ${ }^{39}$ patentees must ensure that their VPM pages are available at the address listed on the physical product at any given point in time, and be able to document this fact. This measure will protect patentees against legal arguments that marking was not continuous and consistent, particularly those that claim that the VPM page was not available at the time a visitor attempted to access it. If the VPM URL listed on the product is unavailable or redirects somewhere other than the VPM webpage, these products may be considered 'unmarked' by a court. Third-party monitoring services currently exist that can record the status of any given URL as frequently as is necessary. In cases where a firm may want to change the URL of their VPM page in the future for any reason, we recommend the use of a permalink that will always redirect to the correct webpage. As a further precaution, we also advise against the use of dynamic webpages for VPMs. Dynamic webpages introduce superfluous components, both in terms of scripting and network requirements, that are unnecessary for VPM compliance. These additional components, and the interactions between them, increase the likelihood that a VPM page becomes inaccessible, or may simply be incompatible with particular browsers.

7. Assessing damages. In order to accurately assess damages in the case of a successful infringement suit, the date that the virtual mark for a particular patent was added to the website is important to document. In the case of physical marks, courts have limited the damages in cases where firms have delayed the marking of their products. ${ }^{40}$ Without evidence that the patent was added to the VPM page at a certain time, patentees risk limiting their potential damages in a similar way. Proving a patent was marked before removal from the

${ }^{39}$ American Medical Systems (n 10)

$40 \mathrm{ibid}$ 
VPM site (e.g., due to expiry) could also be useful in cases were infringement occurring while the patent was in force is only discovered after the patent expired or lapsed. For these reasons, it is important to keep verifiable historical records of the state of the patent marking website (as listed on marked products) by archiving this content at regular intervals. At minimum, archiving should take place at each update to the website. It would be acceptable to use a blockchain to provide a time-stamped and reliable log of changes to the VPM page. ${ }^{41}$

8. Format of the physical mark. The format of the mark, as written on the product, should adhere to the VPM law in each country in which marking is desired. The language of these laws is very clear about these requirements, and these have been applied strictly in the past. ${ }^{42}$ Deviating from the prescribed format may allow an infringer to successfully argue for unintentional infringement and preclude the claiming of any damages before formal notice is given. In the infringement case of $A$ to $Z,{ }^{43}$ the judge concluded that "The [35 USC s 287(a)] statute's language is clear: the website 'together with' either the word 'patent' or 'pat.' must be marked on the item. Plaintiffs' affixing their website to the [item], without including the word 'patent' or the abbreviation thereof, fails to give notice under this subpart." Listing the website alone, in this case, meant the plaintiff was not able to claim damages they could have been entitled to with proper constructive notice.

9. Licensed patents. Firms may use licensed patents in their marked products. If a product manufacturer must, contractually or otherwise, mark a patent on behalf of a licensor, these should be clearly indicated (e.g., with an asterisk) so as not to give the impression that they are the owner of the licensed patent. As knowledge of the patent owner's identity may also be important (e.g., so potentially infringing firms can avoid infringing the owner's related patents), we advise that this identity also be listed.

\section{The future of virtual patent marking: Policy and practice}

We consider the guidelines above to be a bare-minimum to ensure a VPM functions as constructive notice, and, therefore, should be included in any prospective formal standards. However, there are additional actions firms can take in order to make their VPMs as transparent as possible, as well as actions policymakers can take to encourage the adoption of VPMs. We summarise these here.

Under current law, patentees that wish to mark are only required to notify the public about the patents associated with each product. ${ }^{44}$ However, it may also be useful for the public to have access to a list of products associated with each patent. Some patentees mistakenly arrange their VPM pages

\footnotetext{
${ }^{41}$ G de Rassenfosse and KW Higham, 'Decentralising the Patent System' (2019) SSRN Electronic Journal $<$ http://dx.doi.org/10.2139/ssrn.3446337> accessed 3 March 2020.

${ }^{42}$ A to Z Machining Service, LLC (n 17)

43 ibid

${ }^{44}$ It is important to note, however, that the lack of marking (such as the omission of a patent on a VPM page) does not imply the non-existence of a patent.
} 
this way at present. For the reasons described above, we do not advise this. An option to show the relationship in this direction, however, may serve additional purposes. For example, this mode would highlight the use of particular patents across a wide range of products that may indicate a proficiency in IP management that will appeal to investors. Patentees may also provide further metadata about their patents in addition to those contained in our proposed guidelines, such as their expiry dates or current maintenance period (which may be updated in the cases of term extension and renewal events, respectively).

In the interests of transparency, patent marking pages should be indexed by internet search engines. This discoverability is important for two reasons. First, firms may not have easy access to the products they might infringe. This fact is particularly true of firms based in other countries. Without access to the mark, it may be easier to plead unintentional infringement. Second, marking statutes often allow for patent marks to be written on the packaging when it is infeasible to mark the product itself. ${ }^{45}$ In cases where the packaging is not present, but the product name or code is known, it should be made as easy as possible to find information about relevant patents.

From a public policy perspective, there are several steps that governmental and intergovernmental organisations can take to encourage the use and ensure the effectiveness of VPMs. First, these organisations may be able to provide VPM-hosting services that are guaranteed to comply with best-practice guidelines, particularly when the private sector cannot fill this role. As the patent owner would not host these VPM webpages, the privacy concerns noted above are significantly mitigated. This system would also transfer liability for any problems related to continuity and consistency of marking.

In the case where a patent office hosted VPM pages, a two-way connection could be made between product and patent - perhaps going as far as adding product identifiers to patent metadata. This system would be particularly feasible and flexible in a world of distributed-ledger based patent records. ${ }^{46}$ For example, patentees could add their product IDs directly to the patent metadata, and a permalink printed on the product would generate the VPM page automatically. Of course, all of this would be public information (as it is currently) and could be invaluable to researchers and policymakers interested in encouraging commercialisation of patented technology. ${ }^{47}$

Perhaps the most effective way of increasing the short-term adoption of VPMs while assisting with adherence to a particular standard, however, would be for the standard-issuing organisation to construct VPM page templates and make them freely available. This suggestion is particularly important from an accessibility standpoint—patentees who are less web-savvy or legally savvy are currently not as able to take full advantage of the benefits VPMs bestow. Further, these patentees are

\footnotetext{
${ }^{45}$ E.g., 35 USC s 287 (a)

${ }^{46}$ de Rassenfosse and Higham (n 41)

${ }^{47}$ de Rassenfosse (n 16)
} 
most likely individual inventors or small businesses, who are already at a significant disadvantage in patent infringement cases. ${ }^{48}$

The present paper has called for, and laid out the essential components of, a standard for VPMs. While we focus, by necessity, on legislation, case law, and VPM adoption in the United States, most of the issues identified and our recommendations going forward are applicable in all jurisdictions where VPMs are an option. ${ }^{49}$ Ideally, a future standard will be jurisdiction-agnostic. We hope such a standard will help business owners and patent attorneys to make the best use of VPMs and, therefore, contribute to improving the transparency of intellectual property protection across the globe.

${ }^{48}$ JO Lanjouw and M Schankerman, 'Protecting intellectual property rights: are small firms handicapped?' (2004) J.L. \& Econ 47(1), 45-74.

${ }^{49}$ While the United States and United Kingdom have explicitly added VPM provisions to their patent marking laws, in some jurisdictions that have not, such as Australia, VPMs may still function as constructive notice (Liddicoat, n 12). 